\title{
CHOSEN ASPECTS OF THE PRODUCTION OF THE BASIC MAP USING UAV IMAGERY
}

\author{
M. Kedzierski ${ }^{\text {a }}$, A. Fryskowska ${ }^{\text {a }}$ D. Wierzbicki ${ }^{\text {a* }}$, P. Nerc \\ a Department of Remote Sensing and Photogrammetry, Institute of Geodesy, Faculty of Civil Engineering and Geodesy, Military \\ University of Technology, 2 gen. Sylwestra Kaliskiego st., 00-908 Warsaw, Poland \\ (michal.kedzierski, anna.fryskowska, damian.wierzbicki, paulina.nerc@wat.edu.pl)
}

\section{Commission ICWG I/Vb}

KEY WORDS: Photogrammetry, Unmanned Aerial Vehicle, Orthoimage, Geodesy, Mapping

\begin{abstract}
:
For several years there has been an increasing interest in the use of unmanned aerial vehicles in acquiring image data from a low altitude. Considering the cost-effectiveness of the flight time of UAVs vs. conventional airplanes, the use of the former is advantageous when generating large scale accurate ortophotos. Through the development of UAV imagery, we can update largescale basic maps. These maps are cartographic products which are used for registration, economic, and strategic planning. On the basis of these maps other cartographic maps are produced, for example maps used building planning. The article presents an assessesment of the usefulness of orthophotos based on UAV imagery to upgrade the basic map. In the research a compact, nonmetric camera, mounted on a fixed wing powered by an electric motor was used. The tested area covered flat, agricultural and woodland terrains. The processing and analysis of orthorectification were carried out with the INPHO UASMaster programme. Due to the effect of UAV instability on low-altitude imagery, the use of non-metric digital cameras and the low-accuracy GPS-INS sensors, the geometry of images is visibly lower were compared to conventional digital aerial photos (large values of phi and kappa angles). Therefore, typically, low-altitude images require large along- and across-track direction overlap - usually above $70 \%$. As a result of the research orthoimages were obtained with a resolution of 0.06 meters and a horizontal accuracy of $0.10 \mathrm{~m}$. Digitized basic maps were used as the reference data. The accuracy of orthoimages vs. basic maps was estimated based on the study and on the available reference sources. As a result, it was found that the geometric accuracy and interpretative advantages of the final orthoimages allow the updating of basic maps. It is estimated that such an update of basic maps based on UAV imagery reduces processing time by approx. $40 \%$.
\end{abstract}

\section{INTRODUCTION}

Nowadays, the unmanned aerial vehicles (UAV) are a valuable source of the graphic data delivered from the low ceiling. The graphic data gained from a low ceiling are widely used in making the stock-taking of the power lines, surveillance, production of high-resolution orthophoto, and in 3D modelling of the building and cities. Thanks to delivering spatial and time high resolution of images, it is also possible to make current and exact map analysis ( Remondino et al., 2011, Saari et al., 2011, Nex and Remondino,2014; Kedzierski and Wierzbicki, 2015; Wischounig-Strucl and Rinner, 2015). In progress of the continuous development of the non-symmetrical digital cameras, miniaturization of the unmanned aerial vehicles, and automatization of making the orthophotos, the photogrammetry of the low ceiling becomes more widely used. Until now, the cadastral application has mainly used the tachymeter and the GNSS receivers. Thanks to the use of those instruments, it is possible to ensure high accuracy and performance in surveying the object points and lines. In contrast to the traditional research methods, until now, the photogrammetry analysis was used in adaptation and update of the maps for larger areas (Manyoky, et al., 2011). However, the traditional aerial photos have limited application in update of the large-scale maps, mainly due to high height of the flight what results in relatively low resolution of the image and high costs. Considering the profitability of making the map analysis and its accuracy for the hundred hectare areas, decidedly better solution seems to be the use of the low ceiling photogrammetry. Update of the detailed maps is a valuable source for many legal and business use, including the land management, realization of the land management plans, and also update of the cadastral maps. Now, in update of the maps, there can be observed growing interest in use of the low ceiling photogrammetry analysis (Mumbone et al., 2015). The research on use of the UAV in preparing the map adaptation has proved that these analyses are used mainly in update of the large-scale adaptations in the rural areas ( Eisenbeiss, 2011).

A good example can be the area of Albania, where was carried the research on the update of the cadastral maps with the use of UAV for three main areas (Kelm, 2014): Rural mapping applications, Urban mapping applications and Peri-urban applications. For the test rural area, there was made an orthophoto and it was used for the update of the cadastral maps. On the basis of the carrier research, it was confirmed that the UAV technology has wide application in the update of the large-scale detailed and cadastral maps, because in a short time and low costs it delivers high-resolution photogrammetry adaptations. Moreover, the low ceiling photogrammetry adaptations are helpful in the evaluation of the actualness and accuracy of the cadastral maps (Cuningham, et al., 2011).

The research described in this work evaluates the usefulness of UAV orthophotos in update of the cadastral maps.

The article presents the methodology of performing the low ceiling photogrammetry raid in order to make high-resolution orthophoto map for the need of the detailed map update. There was examined the quality and accuracy of the resultative

* Corresponding author - Damian Wierzbicki, dwierzbicki@ wat.edu.pl, +48 226839692 
orthophoto map and there was made an analysis of the possibility of using this map in an update of the large-scale detailed map prepared for the rural areas.

The following section presents the UAV-platform and the camera used in the research. Section 3 describes bundle block adjustment orthorectification mosaicking processes and results. Section 4 describes the results of comparative analysis of UAV orthophoto and basic map. A discussion was undertaken and concluded in the last section of this paper.

\section{UAV PLATFORM AND CAMERA}

The low altitude image data was acquired by a UX5 platform, which can be classified as a mini-sized UAV (Fig. 1.) The airframe allows fully autonomous flight at the desired height at a preset side-lap and over-lap images coverage. The system includes a flight controller enabling real-time flight parameters management.

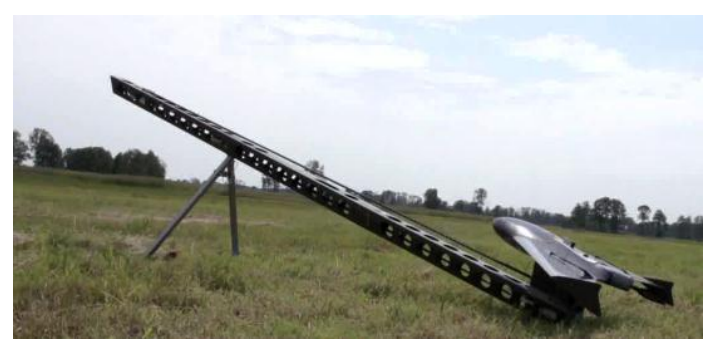

Figure 1. Trimble UX-5 - before flight

UX5 lets the user control the automatic takeoff, flight and landing. Images are taken using an automatic camera shutter release. Safety of flights is controlled automatically, however, it is possible for the operator to intervene by controlling the emergency safety procedures. The takeoff is possible from the mechanical launcher only. The system is operable for wind speed not exceeding $18 \mathrm{~m} / \mathrm{s}$ and in weather conditions no worse than a light rain. The images can be captured from an altitude ranging from 75 to $750 \mathrm{~m}$ with a ground resolution from 2.4 to $24 \mathrm{~cm}$. The image data was obtained by Sony NEX-5R digital camera, which is one of the most commonly selected sensors mounted on board unmanned aerial vehicles. Captured images are saved in JPEG format. For Trimble UX5 platform pictures are taken with a super bright Voigtlander lens with $15 \mathrm{~mm}$ focal length and the maximum aperture equal F4.5. (Wierzbicki et al., 2015)

\section{PHOTOGRAMMETRIC PROCESSING OF UAV-IMAGES}

The aerial mission was realized in good weather and light conditions. The pictures were taken with the 1/2,500 seconds exposure time, from an altitude of $200 \mathrm{~m}$. The digital images were saved in the format of the lossy compression JPEG with radiometry resolution 8bits/channel

\subsection{Test Area}

The chosen test area was the neighbourhood of Chęsne town, located $40 \mathrm{~km}$ northeast of Warsaw (Poland). The terrain was flat, agricultural, and partially wooded.
On the test field, 16 signalized control points and 5 checkpoints were designed and measured with GPS RTK technique with 3 cm accuracy.

\subsection{Bundle Block Adjustment}

For the image data, the bundle block adjustment is the most significant stage of the mutual orientation and absolute orientation of the photos. In the case of the images collected from the low ceiling, their values of the longitudinal and transverse inclination are noticeably larger in relation to the classical, aerial digital photos (Hardin, Jensen, 2011). That is why the image data collected from the low ceiling should characterize with longitudinal and transverse coverage at least $70-80 \%$. An additional aspect is the low accuracy of GPS receivers installed in UAV (Dabrowski et al., 2014). Their accuracy of determining the position is about few meters. That is why the mutual orientation of the images collected from the low ceiling is possible due to the intensive development of Computer Vision techniques. The software dedicated to preparing such type of the date is based on the latest algorithms of adjusting the images, such as Structure from Motion (Westboy, et al., 2012), using the SGM algorithm (Hirschmuller, 2005) and SIFT operator (Lowe, 2004). These solutions also include a variety of software solutions for multiview stereo like SURE (Rothermel, et al., 2012) and PMVS (Furukawa, et al., 2010). The most popular programs processing the low-ceiling photogrammetric data are INPHO UASMaster, Pix4D, AgiSoft Photoscan and EnsoMosaic.. The test block was adjusted in INPHO UASMaster software (Wierzbicki et al., 2015).

In the result of comparing the test block, the average error of the typical observation was $8.1 \mu \mathrm{m}$ (1.6 pix). In this case, the obtained result is satisfactory, considering a large number of the photos in the block. The images were characterized by relatively large values of the angles of the longitudinal and transverse inclination $\left(\omega\right.$ and $\left.\varphi<3^{0}\right)$. The values of the square mean errors for X, Y, Z coordinates were between 0.04-0.14 m. For the independent control points, the values of the mean square errors were $0.06-0.16 \mathrm{~m}$. In the result of comparing such a large block, there were obtained very good results of designating the coordinates of the views centre $\mathrm{X}_{0}, \mathrm{Y}_{0}, \mathrm{Z}_{0}$.

The values of the standard deviations were between $0.10-0.13$ $\mathrm{m}$. However, the accuracy of designating the angle elements of the external orientation was from $0.008^{\circ}$ to $0.029^{\circ}$. The results of the adjustment are included in Table 1.

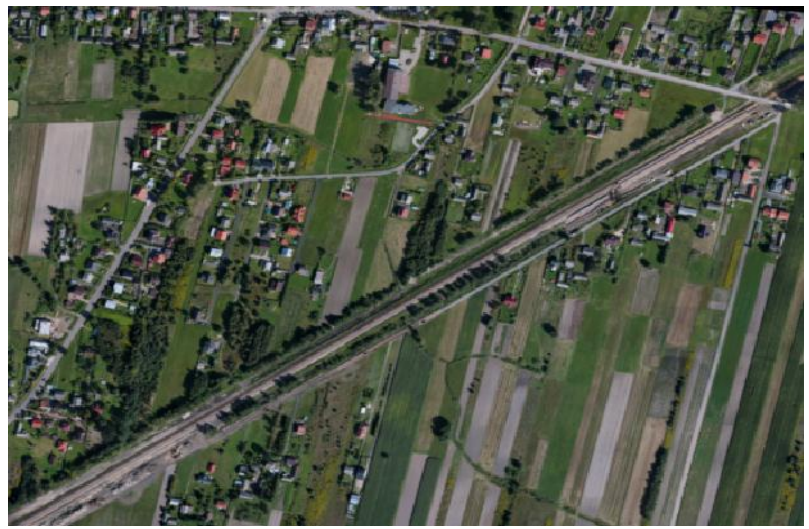

Figure 2. Orthophotomosaic- fragment of the test area 


\begin{tabular}{|c|c|c|}
\hline \multicolumn{2}{|l|}{ Description } & Images block \\
\hline \multicolumn{2}{|c|}{ Number of photos } & 3551 \\
\hline \multicolumn{2}{|c|}{$\sigma_{0}[\mu \mathrm{m}] /[\mathrm{pix}]$} & $8.1 / 1.6$ \\
\hline \multicolumn{2}{|c|}{ Number of GCPs } & 16 \\
\hline \multicolumn{2}{|c|}{$\begin{array}{l}\text { Number of tie } \\
\text { points }\end{array}$} & 5 \\
\hline \multirow{3}{*}{$\begin{array}{c}\text { Average } \\
\text { a'priori error } \\
\text { for GCPs and } \\
\text { check points } \\
\mathrm{X}, \mathrm{Y}, \mathrm{Z},[\mathrm{m}]\end{array}$} & $\mathbf{X}$ & 0,03 \\
\hline & $\mathbf{Y}$ & 0,03 \\
\hline & $\mathbf{Z}$ & 0,03 \\
\hline \multirow{3}{*}{$\begin{aligned} & \text { GCPs } \\
\mathbf{X}, \mathbf{Y}, \mathbf{Z}[\mathrm{m}] & \\
& \mathbf{R M S}\end{aligned}$} & $\mathbf{X}$ & 0.04 \\
\hline & $\mathbf{Y}$ & 0.05 \\
\hline & $\mathbf{Z}$ & 0.14 \\
\hline \multirow{3}{*}{$\begin{array}{c}\text { Check points } \\
\text { X, Y, Z [m] } \\
\text { RMS }\end{array}$} & $\mathbf{X}$ & 0.15 \\
\hline & $\mathbf{Y}$ & 0.06 \\
\hline & $\mathbf{Z}$ & 0.16 \\
\hline \multicolumn{2}{|l|}{$\mathbf{M X}_{0}[\mathrm{~m}]$} & 0.13 \\
\hline \multicolumn{2}{|l|}{$\mathbf{M Y}_{0}[\mathrm{~m}]$} & 0.10 \\
\hline \multicolumn{2}{|l|}{$\mathrm{MZ}_{0}[\mathrm{~m}]$} & 0.11 \\
\hline \multicolumn{2}{|l|}{$\mathbf{M} \omega\left[^{\circ}\right]$} & 0.024 \\
\hline \multicolumn{2}{|l|}{ М $\left[^{\circ}\right]$} & 0.029 \\
\hline \multicolumn{2}{|l|}{ Мк $\left[{ }^{\circ}\right]$} & 0.008 \\
\hline
\end{tabular}

Table 1. Bundle Block Adjustment - results

\subsection{Digital Terrain Model Extraction and Orthorectification}

Generating the Digital Terrain Model and Orthorectification were made in a Surface module and UASMaster software. Generating the model begins from generating the cloud of points. It is based on algorithm Cost Based Matching (Saile, 201). In the initial stage of preparing the model, a key aspect is the choice of the correct parameters of the resolution of the resultative model, depending on the quality of the images and terrain characteristics, and also filtration and classification of points in the cloud. The largest problems with DTM edition appeared in the forest and strongly urbanized areas. On the basis of the clouds of points, the Digital Surface Models were generated with resolution $20 \mathrm{x}$ GSD, that is $1.2 \mathrm{~m}$. The quality of the generated Digital Terrain Model has a key meaning in the process of orthorectification, and also the accuracy of the final product. Generating the orthophoto map on the basis of images collected from the low ceiling, does not differ in the initial stage of processing from the way of rectification of the traditional aerial photos. In processing the low-ceiling image data, the quality of the resultative orthoimages is influenced by the use of the non-symmetrical digital camera that obtains the images of noticeably lower radiometric quality in comparison to the classical photogrammetric cameras. The other factors that influence the quality of the images are also blurring of the image with not enough long time of exposure in relation to the UAV speed, and also potential occurence of the image vignetting.
In the software dedicated to processing the low-ceiling image data, the process of the orthorectification is fully automated. In the case of this analysis, the basic parameters that had to be defined were the terrain level of the resultative pixel of the orthophoto and the format of the resultative file. The next stage in the orthorectification is tilling the orthophotos, that is made automatically. It is based on the mutual connection of the particular orthophotos in larger units, with considering the tonal adjustment. The tilling process consisted of two stages: the first stages included the designation of the tilling line. However, the second stage included the correction of the radiometry of the connected orthophotos. Within the research, there was made a resultative orthophoto map for the testing area (Figure 2.)

Often, the orthomosaics generated in this way have errors in the form of shifted pixels in the tilled orthophotos. This occurrence is frequent in case of using, so called closed algorithms, used in processing the low-ceiling image data without the operator's interference in the adjustment process (Turner et al., 2012).

The verification of the geometric quality was made in the resultative orthophoto map. It was about making an absolute evaluation of the accuracy related to the independent control measurement. The accuracy of the orthophoto map can be given by mean square error:

$$
m_{\text {ortho }}=\sqrt{\frac{[d d]}{n}}
$$

where

$d$-deviation value understood as the length of the shift vector of the control element identified on the orthophoto map in relation to the location designated from the independent control measurement,

$n$ - number of control points

For the evaluation of the geometric orthophoto map accuracy, there were used independent control points that did not participated in the adjustment. On the basis of the carried analysis, the accuracy of the resultative orthophoto map GSD= $0.06 \mathrm{~m}$ was 2 pixels at the average, so about $0.10 \mathrm{~m}$. This accuracy was estimated on the basis of the analysis of the accuracy of the particular stages of the orthophoto map generation (Kedzierski et al., 2014).

\section{COMPARATIVE ANALYSIS OF UAV ORTHOPHOTO AND BASIC MAP}

The detailed map of Poland is made in scales 1: $500-1: 1000$ for the high-urbanized areas (e.g. dense building or a large number of underground installations), $1: 1000-1: 2000$ for medium-urbanized areas, and 1:5000 for the forest and agricultural areas. For the detailed map, the accuracy of measuring the terrain details included in so called, first group (among other, administrative boundaries, boundaries of plots and buildings) is $\pm 0.10 \mathrm{~m}$. For the measurements of the detailed included in the second group (among other, parks, playing fields, underground territorial development), the accuracy is $\pm 0.30 \mathrm{~m}$. However, for the third group (among other, the boundaries of the utilities, contours of the ground classification, surface division), the accuracy is $\pm 0.50 \mathrm{~m}$. See Table 2 . 


\begin{tabular}{|c|c|}
\hline Accuracy group & RMSE [m] \\
\hline I & \pm 0.10 \\
\hline II & \pm 0.30 \\
\hline III & \pm 0.50 \\
\hline
\end{tabular}

Table 2. The accuracy groups of the terrain details for the basic map of Poland

Verification of the UAV orthophoto map was made on the basis of the comparative analysis of the terrain details coordinated that were gained from the numerical detailed map prepared for the Chęsne premises. The numerical detailed map was used as a source data. The analysis of the accuracy of location of the particular objects was made using the examples of building, plots, roads, and location of other infrastructure elements of the terrain such as: fences, plot boundaries, and elements of the territorial development) (Kedzierski et al., 2015). (Tab. 3)

\begin{tabular}{|c|c|c|}
\hline Object type & $\begin{array}{c}\text { The } \\
\text { accuracy } \\
\text { of object } \\
\text { identification } \\
\text { on the map } \\
\text { [\%] }\end{array}$ & RMSE [m] \\
\hline Building & 94 & 0.09 \\
\hline $\begin{array}{c}\text { Boundaries } \\
\text { of the plots }\end{array}$ & 78 & 0.19 \\
\hline $\begin{array}{c}\text { Boundaries } \\
\text { of roads }\end{array}$ & 92 & 0.23 \\
\hline $\begin{array}{c}\text { Other } \\
\text { elements of } \\
\text { terrain } \\
\text { infrastructure }\end{array}$ & 76 & 0.13 \\
\hline
\end{tabular}

Table 3. The results of a comparative analysis of the ortho and basic map

On the basis of the accuracy analysis it can be declared that for all the accuracy groups of the detailed map, UAV ortho gives sufficient accuracy in the update and identification of the objects on the detailed map. The worst result was obtained in the case of identifying the boundaries of the roads. The obtained RMSE was, in this case, $\pm 0.23 \mathrm{~m}$. On the basis of the obtained results, it can be said that in most cases, the criteria are fulfilled for the second and the third accuracy group. However, in some cases, there can occur the obstruction in reaching the $0.10 \mathrm{~m}$ accuracy.

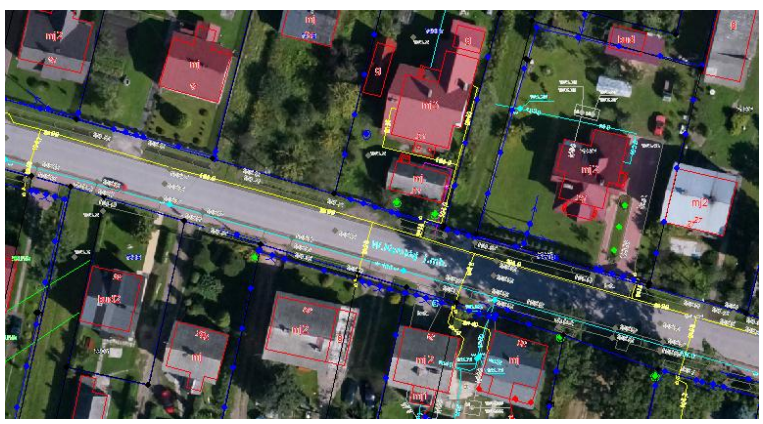

Figure. 3 Updated basic map based on UAVs ortho

On the above-given figure (Fig. 3) there was given an example of identifying the particular objects on the detailed map.

\section{CONCLUSIONS}

The data obtained from UAV can be a very good source for an update of the detailed maps of the rural areas. The accuracy of the resultative orthophoto map was 2 pixels. The obtained accuracy is sufficient for an update of rural areas map. The methodology of producing the low-ceiling orthophoto map offers a great potential in order to obtain the image data for the needs of updating the detailed maps of the rural areas. The advantage for the users of the detailed maps is also the possibility of obtaining UAV ortho for areas hard to reach. In the places where tachymetry or GNSS measurements are impossible to do. Thanks to the development of UAV technology it is possible to improve the data acquisition for the needs of updating the detailed maps. Reliable automation of the orientation and correction of the blocks of photos obtained from low ceiling ensures shortening of the time of making the measurements even by $40 \%$. What is more, the costs of adjustment seem to be noticeably lower in relation to the classical measurement techniques. In the future, the UAV adjustment will be used everywhere where high adjustment accuracy is needed at possibly the shortest time of obtaining and processing the data.

\section{ACKNOWLEDGEMENTS}

This paper has been supported by the Military University of Technology, the Faculty of Civil Engineering and Geodesy, Department of Remote Sensing and Photogrammetry as a research project 933/2016.

\section{REFERENCES}

Cunningham, K., Walker, G., Stahlke, E., Wilson, R. 2011. Cadastral Audit and Assessments Using Unmanned Aerial Systems.'. Proceedings of ISPRS and UAV-g, Zurich, Switzerland

Dabrowski R., Delis P., Wyszynski M., 2014. Analysis of the possibility of using a video camera as a UAV sensor. 9th International Conference "Environmental Engineering", 22-23 May 2014, Vilnius, Lithuania, SELECTED PAPERS, eISSN 2029-7092

Furukawa, Y., Curless, B., Seitz, S. M., Szeliski, R. 2010. Towards internet-scale multi-view stereo. In Computer Vision and Pattern Recognition (CVPR), 2010 IEEE Conference on (pp. 1434-1441). IEEE.

Hardin, P.J., and Jensen, R.R. 2011. Small-scale unmanned aerial vehicles in environmental remote sensing: challenges and opportunities. GIScience \& Remote Sensing. 48(1): 99-111

Hirschmüller H., 2005. Accurate and efficient stereo processing by semi-global matching and mutual information. Proceedings of the IEEE Computer Society Conference on Computer Vision and Pattern Recognition (CVPR). Tom 2. San Diego, CA, USA, pp. 807-814.

Lowe, D. 2004 Distinctive Image Features from Scale-Invariant Keypoints. International Journal of Computer Vision. Vol. 60, No. 2, pp. 91-110.

Kedzierski M., Fryekowska A., Wierzbicki D., 2014 Opracowania fotogrametryczne z niskiego pulapu, Redakcja 
Wydawnictw Wojskowej Akademii Technicznej, Warszawa, ISBN 978-83-7938-047-3 (in Polish)

Kedzierski, M., Wierzbicki, D., 2015. Radiometric quality assessment of images acquired by UAV's in various lighting and weather conditions. Measurement, 76, 156-169.

Kedzierski M., Fryskowska A., Wierzbicki D., Delis P., Cadastral Mapping based on UAV Imagery, Proceedings of 15th International Scientific and Technical Conference „From Imagery to map: digital photogrammetric Technologies”, 2629.10.2015 Yucatan, Mexico, p. 12-15.

Kelm, K. 2014. UAVs Revolutionise Land Administration. GIM International, 28(10), 35-37.

Manyoky, M., Theiler, P., Steudler, D., \& Eisenbeiss, H. 2011. Unmanned aerial vehicle in cadastral applications. ISPRSInternational Archives of the Photogrammetry, Remote Sensing and Spatial Information Sciences, 3822, 57.

Mumbone, M., Bennet, R., Gerke, M., Volkmann, W. 2015. Innovations in boundary mapping: Namibia, customary lands and UAVs, World Bank conference on land and poverty, Washington DC

Nex, F., Remondino, F., 2014. UAV for 3D mapping applications: a review. Applied Geomatics, 6(1), 1-15.

Remondino, F., Barazzetti, L., Nex, F., Scaioni, M., \& Sarazzi, D., 2011. UAV photogrammetry for mapping and $3 \mathrm{~d}$ modelingcurrent status and future perspectives. International Archives of the Photogrammetry, Remote Sensing and Spatial Information Sciences, 38(1), C22.

Rothermel, M., Wenzel, K., Fritsch, D., \& Haala, N. 2012. Sure: Photogrammetric surface reconstruction from imagery. In Proceedings LC3D Workshop, Berlin (pp. 1-9).

Saari, H., Pellikka, I., Pesonen, L., Tuominen, S., Heikkilä, J., Holmlund, C., Antila, T., 2011. Unmanned Aerial Vehicle (UAV) operated spectral camera system for forest and agriculture applications. In SPIE Remote Sensing (pp. 81740H$81740 \mathrm{H})$. International Society for Optics and Photonics.

Saile J., 2011 High Performance Photogrammetric Production, Photogrammetric Week 2011, pp.21-27;

Turner, D., Lucieer, A., Watson, C. 2012. An automated technique for generating georectified mosaics from ultra-high resolution unmanned aerial vehicle (UAV) imagery, based on structure from motion (SfM) point clouds. Remote Sensing, 4, 1392-1410;

Westoby, M. J., Brasington, J., Glasser, N. F., Hambrey, M. J., ,Reynolds, J. M. 2012. 'Structure-from-Motion' photogrammetry: A low-cost, effective tool for geoscience applications. Geomorphology, 179, 300-314.

Wierzbicki, D., Kedzierski, M., Fryskowska, A. 2015. Assesment of the influence of uav image quality on the ortophoto production ISPRS-International Archives of the Photogrammetry, Remote Sensing and Spatial Information Sciences, 1, 1-8.
Wischounig-Strucl, D., Rinner, B., 2015. Resource aware and incremental mosaics of wide areas from small-scale UAVs. Machine Vision and Applications, 1-20.

Revised June 2015 